\title{
Watery and dark axons in Wallerian degeneration of the opossum's optic nerve: different patterns of cytoskeletal breakdown?
}

\author{
MARCELO S. NARCISO ${ }^{1}$, JAN NORA HOKOÇ ${ }^{2}$ and ANA M. B. MARTINEZ ${ }^{1}$ \\ ${ }^{1}$ Departamento de Histologia e Embriologia, \\ Instituto de Ciências Biomédicas, CCS - UFRJ, 21941-590 Rio de Janeiro, RJ. \\ ${ }^{2}$ Laboratório de Neurobiologia da Retina, Instituto de Biofísica Carlos Chagas Filho, \\ Centro de Ciências da Saúde, Universidade Federal do Rio de Janeiro, Brasil \\ Manuscript received on December 18, 2000; accepted for publication on April 11, 2001; \\ presented by LENY A. CAVAlCANTE
}

\begin{abstract}
In this paper we report a qualitative morphological analysis of Wallerian degeneration in a marsupial. Right optic nerves of opossums Didelphis marsupialis were crushed with a fine forceps and after 24, 48, 72, 96 and 168 hours the animals were anaesthetized and perfused with fixative. The optic nerves were immersed in fixative and processed for routine transmission electron microscopy. Among the early alterations typical of axonal degeneration, we observed nerve fibers with focal degeneration of the axoplasmic cytoskeleton, watery degeneration and dark degeneration, the latter being prevalent at 168 hours after crush. Our results point to a gradual disintegration of the axoplasmic cytoskeleton, opposed to the previous view of an "all-or-nothing" process (Griffin et al 1995). We also report that, due to an unknown mechanism, fibers show either a dark or watery pattern of axonal degeneration, as observed in axon profiles. We also observed fibers undergoing early myelin breakdown in the absence of axonal alterations.
\end{abstract}

Key words: ultrastructure, nerve fiber, crush lesion, watery degeneration, dark degeneration, marsupial.

\section{INTRODUCTION}

The sequence of events described by Waller in 1850 , which promotes a complete destruction of the distal segment of a cut peripheral nerve (then called Wallerian degeneration - WD), has been a subject of intense investigations using different approaches and animal models. Although the mechanism which initiates this process is starting to be unraveled, there are still controversies concerning many aspects of WD, such as the spatial-temporal pattern (Donat and Wisniewski 1973, Cook and Wisniewski 1987, Carrol et al. 1992, Hall 1993), differences of degen-

Correspondence to: Dr. Ana M.B. Martinez

E-mail: martinez@chagas.biof.ufrj.br eration between small- and large-sized myelinated nerve fibers and between motor and sensory nerves or even between different animal models and types of injury (Crevel and Verhaart 1963, Lin and Ingram 1973, Cook et al. 1974, Cook 1978, Ishise and Rosenbluth 1986, Lunn et al. 1990, Carbonell et al. 1991, Guillery and Taylor 1993, Guillery and Cavalcante 1995, Frank and Wolburg 1996). One aspect that has not received much attention concerns different types of axonal degeneration, which is frequently observed in the CNS fibers as shall be described below.

One of the first changes occurring in the lesioned axon is the granular disintegration of the cytoskeleton, when axoplasmic microtubules (MT) 
and neurofilaments (NF) are converted into an amorphous and granular material (Waxman et al. 1992, 1993, Griffin and Hoffman 1993). In the CNS the cytoskeletal breakdown is thought to promote two morphological aspects of axoplasmic degeneration: (1) "dark degeneration", in which axons become dark, with dense axoplasm, and its content of organelles is very difficult to distinguish, and (2) "watery degeneration", in which axons become pale, enlarged and the axoplasm is either replaced by an amorphous and granular material or is completely devoid of organelles (Kruger and Maxwell 1969, Cook et al. 1974, Bignami et al. 1981, Malbouisson et al. 1984, Cook and Wisniewski 1987, Hasegawa et al. 1988). In the PNS however, only "watery degeneration" has been described in the literature (Malbouisson et al. 1984, 1985). According to some authors, axons undergoing dark degeneration are frequently of medium or small caliber, watery degeneration being more commonly observed in large axons (Cook et al. 1974, Carrol et al. 1992). Moreover, dark degeneration has only been observed in myelinated nerve fibers (Cook et al. 1974). However, it was never explained why central fibers exhibit both types of axoplasmic disintegration and why peripheral fibers exhibit only watery degeneration. Further, the factors that would explain why a certain fiber would undergo one type of degeneration and not the other are still not known.

In this study, we performed an ultrastructural qualitative analysis of the early aspects of WD in the optic nerve of the opossum Didelphis marsupialis. The optic pathways of this animal (which has proven to be a good experimental model for Neurobiology studies) and other marsupial species have been analyzed with different techniques and approaches (Hokoç and Oswaldo-Cruz 1978, Kirby et al. 1982, Allodi et al. 1990, Cavalcante et al. 1991, 1992). In our work we produced an experimental injury by crushing the optic nerve, and observed the ultrastructural alterations at different periods of time after the lesion. Particular emphasis was given to the two patterns of axoplasm degeneration.

\section{MATERIAL AND METHODS}

Twelve young adult opossums Didelphis marsupialis, $350 \mathrm{~g}$ to $1,8 \mathrm{~kg}$, were used in this study. All of the proceedings adopted for animal use were according to "The principles of laboratory animal care" and approved by the commission of animal care of the Instituto de Biofísica / UFRJ.

\section{Surgical Procedures}

The animals were deeply anaesthetized, with pentobarbital (30 mg/ml/kg, intraperitoneal) or alphaxalone (Saffam, $9 \mathrm{mg} / \mathrm{kg}$, intraperitoneal). After lateral canthotomy, an incision was made in the fibrous connective tissue posterior to the right orbit, and the retrobulbar muscles and the periorbital fat tissues were carefully dissected in order to expose the initial segment of the optic nerve. The right optic nerve was crushed $2 \mathrm{~mm}$ distal to the eye under moderate pressure for approximately 15 seconds, with a fine forceps. This procedure was made with maximum care in order to avoid injury of the retinal vessels that follow a parallel pathway in the beginning of the optic nerve. After the crush, the circumjacent tissues and the skin were sutured and the animals were returned to their cages, where they stayed for different periods of time $(24,48,72,96$ and 168 hours after crush).

\section{Electron Microscopy Processing}

After the above periods of time, the animals were deeply anaesthetized with Pentobarbital (intraperitoneal), and prepared for cardiac perfusion. The animals were initially perfused with $0.9 \%$ saline (around $300-500 \mathrm{ml}$ per animal), followed by $4 \%$ paraformaldehyde ( $\mathrm{pH} 7.4$ ) in $0.1 \mathrm{M}$ phosphate buffer (around 300-500 $\mathrm{ml}$ per animal). The average time of perfusion varied from 30 to 40 minutes.

After perfusion, the head of the animal was removed and the optic nerves were dissected out from the ocular globe to the optic chiasma. Two mm-long fragments used for cross sectioning were obtained from the distal segment, one fragment near the crush site and other near the optic chiasma. The distance 
between these two pieces of nerve was $2.0 \mathrm{~cm}$. The fragments used for longitudinal sections were $3 \mathrm{~mm}$ long and were obtained from the region between the fragments used for cross sections. The left optic nerves were used as a control, and their fragments obtained were of the same size and at the same positions of the crushed nerves. All the fragments were immersed into a fixative solution containing $2.5 \%$ glutaraldehyde and $4 \%$ paraformaldehyde in $0.1 \mathrm{M}$ phosphate buffer ( $\mathrm{pH} 7.4$ ), were washed in the same buffer, postfixed in $1 \% \mathrm{OsO}_{4}$ for 1 hour, dehydrated in a graded series of acetone, infiltrated in Poly/Bed 812 resin (Polysciences, Inc.) and polymerized at $60^{\circ} \mathrm{C}$ for 48 hours. Ultrathin sections $(60-70 \eta \mathrm{m}$ thick) were obtained on a RMC ultramicrotome, collected on copper grids, stained with uranyl acetate and lead citrate and observed and photographed on a Zeiss 900 Transmission Electron Microscope.

\section{RESULTS}

\section{Controls}

The ultrastructure of the optic nerves used as control (the left ones) exhibited fibers of normal aspect, in cross and longitudinal sections (see Hokoç and Oswaldo-Cruz 1978 and Peters et al. 1991), showing no influence of the crush in the contralateral side.

\section{Surgically crushed specimens:}

After careful observation of sections from proximal and distal fragments we could not detect any difference between them. This was true for all stages studied.

\section{HOURS AFTER CRUSH}

In cross sections, the general organization of the optic nerve was maintained, most fibers exhibiting a regular outline, aggregated in fascicles separated by astrocytic septa. In some areas it was possible to visualize an increase of astrocytic processes and perikaryal hypertrophy. There were few fibers with altered axoplasmic cytoskeletal contents, represented by focal disintegration of the cytoskeleton. Occasionally we observed fibers in which there was a complete absence of cytoskeletal elements characterizing the watery degeneration (Fig. 1A). Few medium- or small-sized nerve fibers showed the axoplasm filled with an amorphous, granular and dark material, representing what is described as dark degeneration (Fig. 1B).

In most fibers the myelin sheath did not show significant alterations at this stage. However in fibers exhibiting watery degeneration, the myelin was very thin, probably due to an accommodation to the enlargement occurred at these fibers (fig. 1A). Rare fibers showed partial or total disintegration of myelin, sometimes in the presence of normal axoplasm. Myelin debris was observed inside vacuoles in the cytoplasm of astrocytes (not illustrated).

\section{HOURS AFTER CRUSH}

Astrocytic processes were thick and prominent among the fibers, leading to disorganization of the nerve fascicles. Astrocyte perikarya as well as their processes exhibited thick bundles of intermediate filaments. Although most nerve fibers were still preserved, some degenerating nerve fibers were observed and showed the same alterations observed at 24 hours after crush. Some fibers presented focal degeneration of the cytoskeleton, which in longitudinal sections corresponded to enlarged areas of the axoplasm (fig. 1C). Others fibers exhibited a dense axoplasm, looking as if they were in the process of dark degeneration (fig. 1D). Myelin breakdown areas were sparse producing globular debris which were observed inside astrocytes perikarya and processes (not illustrated).

\section{HOURS AFTER CRUSH}

Here the observed alterations were clearly more intense than at previous stages. One of the most striking alterations was an increasing disorganization of the nerve structure, due to the invasion of astrocytic processes among the nerve fibers (fig. 2A). Filament bundles filled these processes, and some of them showed lipid droplets and myelin lamellae (not illustrated) debris in the cytoplasm, suggesting myelin phagocytosis. Normal profiles of fibers were 


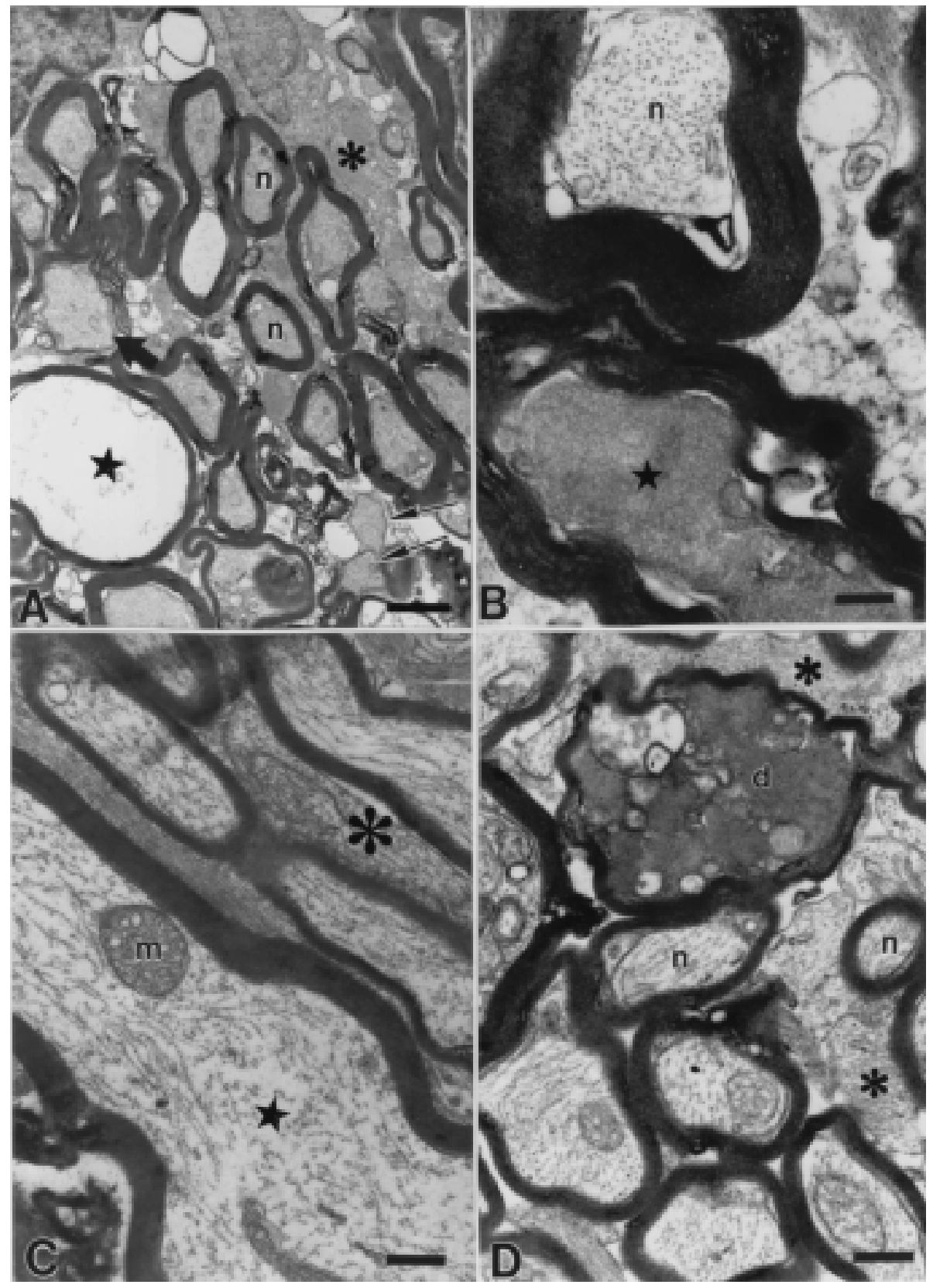

Fig. 1 - Ultrathin sections of opossum's optic nerve fibers, 24 (A and B) and 48 hours (C and D) after crush. A. Normal fibers (n) are seen among some altered fibers, which exhibit watery degeneration (star) and myelin sheath breakdown (thick arrow). Note demyelinated fibers (thin arrows) with an apparently intact axoplasmic cytoskeleton. Asterisk, astrocytic processes. Bar $=1.7 \mu \mathrm{m}$. B. Normal looking optic nerve fiber $(\mathrm{n})$ is seen above an optic fiber showing dark degeneration (star). Bar $=0.4 \mu \mathrm{m}$. C. Longitudinal section of optic nerve fibers showing areas of focal degeneration of the axoplasmic cytoskeleton (star). Asterisk, astrocytic processes; $\mathrm{m}$, mitochondrial profile. $\mathrm{Bar}=0.6 \mu \mathrm{m}$. D. Observe optic nerve fibers with an apparently normal appearance $(\mathrm{n})$. Among them, there is a fiber with dense axoplasm and some altered organelles, typical of dark degeneration (d). Asterisks, astrocytic processes. Bar $=$ $0.6 \mu \mathrm{m}$. 


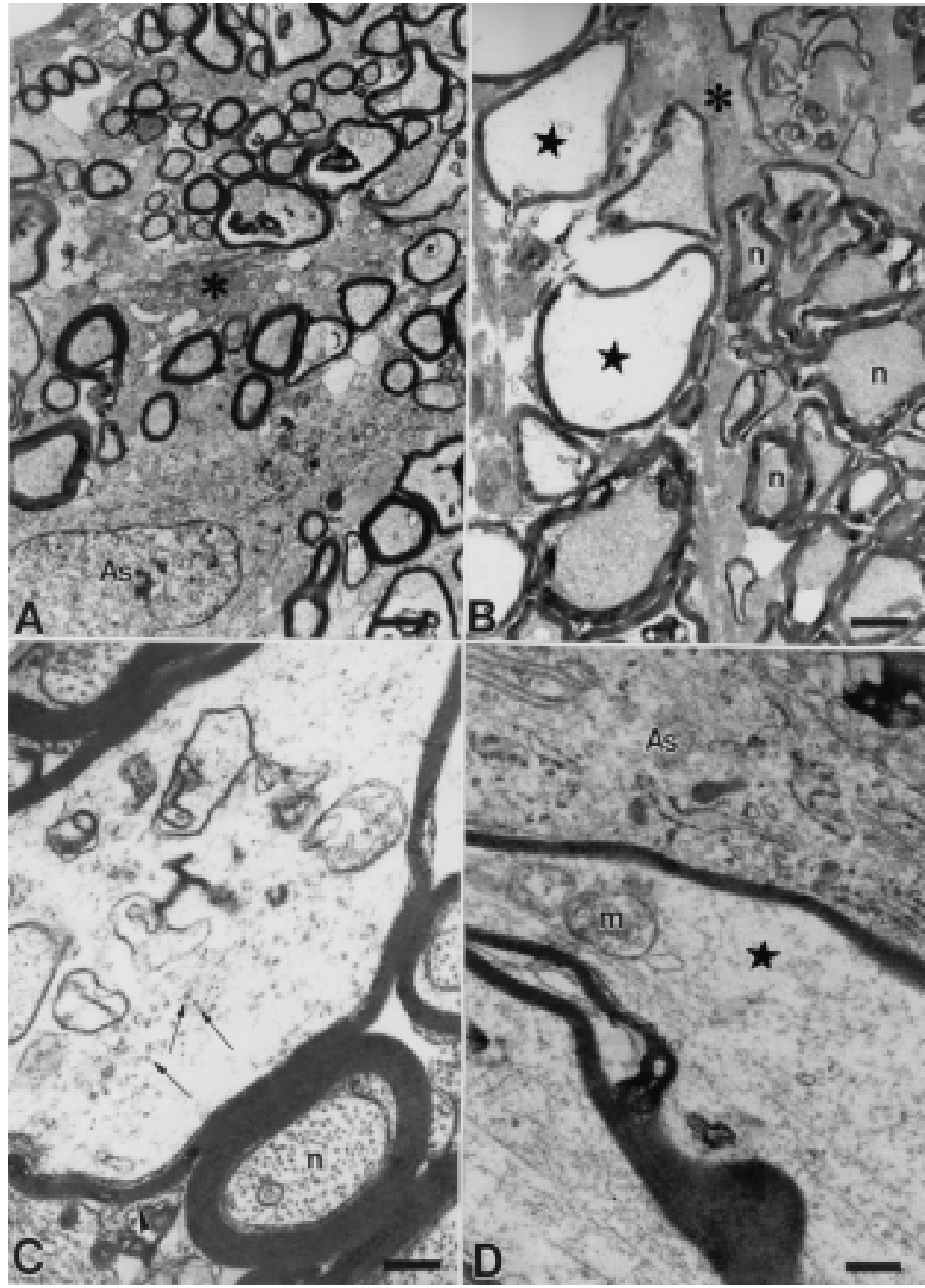

Fig. 2 - Electron micrographs of opossum's optic nerve fibers undergoing Wallerian degeneration, 72 hours after crush. A. General view of the optic nerve. Note the profuse astrocytic septa (asterisk) causing a severe disorganization of the optic fibers. Many fibers have an apparently normal appearance in this field. As, astrocyte nucleus. Bar $=1.7 \mu \mathrm{m}$. B. Optic nerve fibers exhibiting an apparently normal axoplasm (n), but there is some distortion of their myelin sheath. We can also observe a fascicle in which fibers are undergoing watery degeneration (stars) and show increased volume with no discernible organelle in the axoplasm. Asterisk, astrocytic processes. Bar $=$ $1.7 \mu \mathrm{m}$. C. Optic nerve fiber showing reduction of axoplasmic content associated with presence of altered membranous organelles. Few microtubules (small arrows) can be seen in the axoplasm. The myelin sheath (arrowhead) is thin due to the increased axoplasmic volume, suggesting watery degeneration. Note a small-sized fiber (n) with an apparently normal appearance. Bar $=0.4 \mu \mathrm{m}$. D. Longitudinal section of optic nerve fibers showing areas of focal degeneration represented by rarefaction of the cytoskeleton (star). Some components of the cytoskeleton can still be seen in the axoplasm. An astrocytic soma (As) is also seen. m, mitochondrial profile. Bar $=0.6 \mu \mathrm{m}$ 
still present in the nerve fascicles (fig. 2B).

Some fibers showed partial dissolution of the cytoskeleton (fig. 2D). The majority however, presented either watery degeneration with distended axoplasm (fig. 2B) and degenerating organelles (fig. 2C) (or even without organelles), or dark degeneration represented by dark fibers with granular and dense axoplasm. Many fibers with accumulation of cytoplasmic organelles were observed.

Another remarkable feature of this stage was myelin breakdown. Fibers of different sizes showed detachment and vacuolization of myelin lamellae, causing axolemmal exposure. Some fibers were completely deprived of their ensheathment, and their axons exhibited either altered organelles or no discernible organelle in the axoplasm. Microglial cells were seen in the neighborhood of demyelinated fibers; these cells were characterized by their scanty cytoplasm and a long, heterochromatic nucleus (not illustrated).

\section{HOURS AFTER CRUSH}

The alterations presented in the optic nerve at 96 hours after crush were very similar to those observed at 72 hours after crush. Nerve fascicles still exhibited dispersed fibers due to the increasing penetration of astrocytic processes among them, causing disorganization of the optic nerve structure (fig. 3A). Some profiles of different sizes still presented a normal ultrastructural pattern (fig. 3A). There was an increase of degenerating fibers exhibiting either the dark (fig. 3B) or watery pattern. Myelin breakdown was quite frequent in many regions of the nerve (fig. 3C). This observation was accompanied by the presence of several microglial cells (fig. 3C). However, degenerating material was still clearly visualized inside cytoplasm and processes of astrocytes (fig. 3D).

\section{HOURS AFTER CRUSH}

The degenerative changes presented at 168 hours after crush were the most prominent among all the analyzed stages, because almost all optic nerve fibers were altered and only rare fibers showed a normal appearance (fig. 4A). The hyperfilamentous astrocytic processes produced a complete disarrangement of the nerve fascicles, forming irregular septa among the fibers (fig. 4A). A remarkable feature of this stage was the prevalence of dark fibers, as compared to watery fibers (fig. 4A). These dark fibers were frequently seen very close to astrocytes and microglial cells, suggesting gradual phagocytosis by these cells (figs. 4B and 4D). There were many degenerating fibers showing myelin breakdown, with detached and vacuolized lamellae. Microglial cells were frequently observed and exhibited many vacuoles in their cytoplasm. Although there was an apparent increase in microglial cells, myelin debris were still observed inside vacuoles in the cytoplasm of astrocytes. We could also observe at this stage evidence of oligodendrocyte phagocytosis (fig. 4C), suggesting that these cells also have phagocytic activity during the process of WD. Oligodendrocytes were ultrastructurally characterized by their heterochromatic nuclei and dark cytoplasm in which we could distinguish microtubules.

\section{DISCUSSION}

Our study is a qualitative ultrastructural analysis of the main early alterations found in opossums' optic nerves undergoing WD after surgical crush. The results obtained here are comparable to what is known from other vertebrates in terms of the general axonal responses to trauma. In our study, 3 types of degenerative axoplasm pattern could be characterized in the crushed nerve fibers: (1) focal degeneration of the cytoskeleton; (2) watery degeneration; and (3) dark degeneration. These 3 patterns of degenerating axons were observed simultaneously in all stages used in our study, and although there was no apparent predominant form in the initial stages of this process, at 168 hours (1 week) after crush, there was a clear increment of fibers undergoing dark degeneration.

The granular disintegration of the cytoskeleton is one of the first alterations observed in fibers undergoing WD and represents cytoskeletal cleav- 


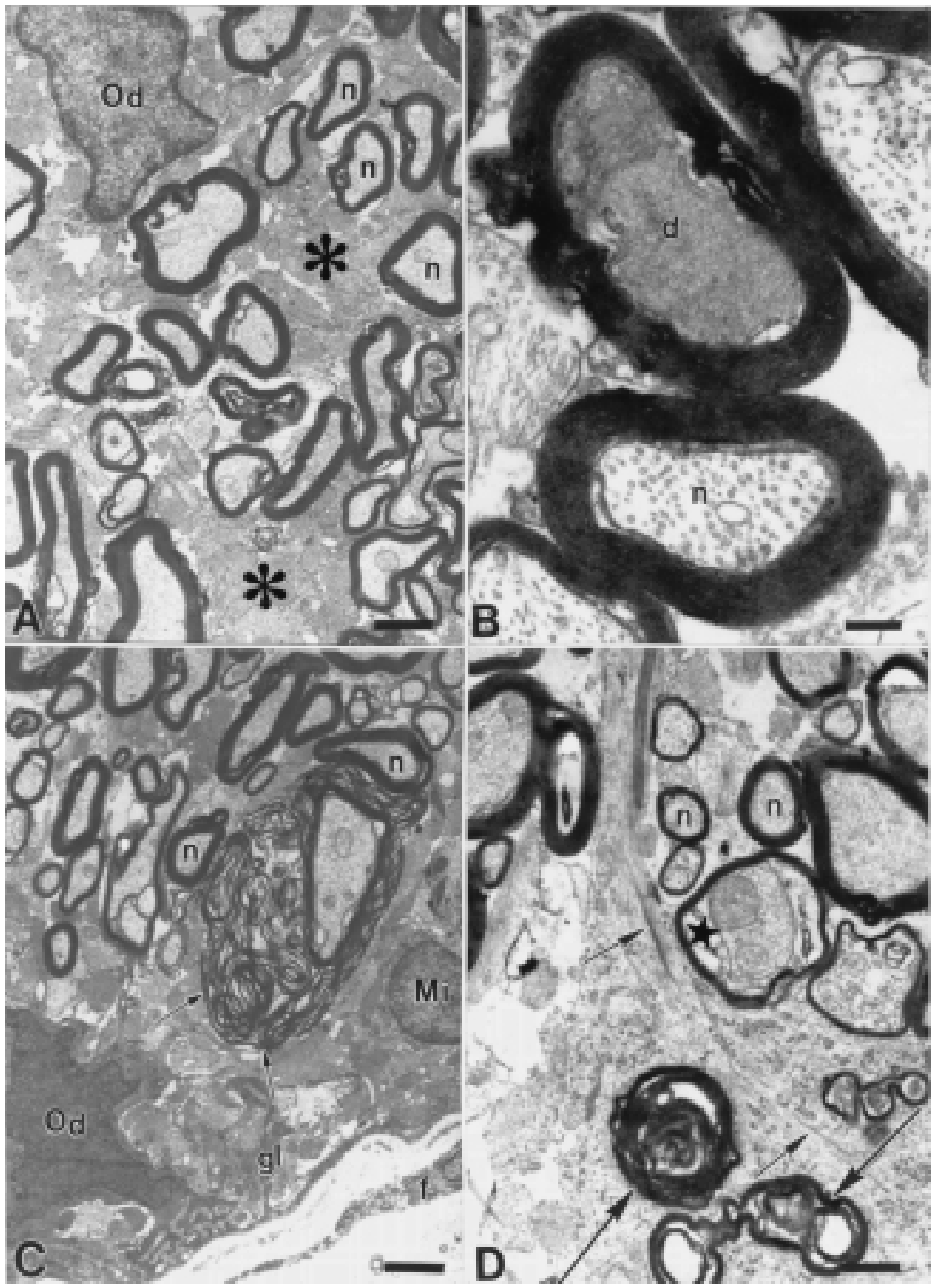

Fig. 3 - Electron micrographs of opossum's optic nerve fibers undergoing Wallerian degeneration 96 hours after crush. A. Thick septa with abundant astrocytic processes (asterisks) are seen among the optic fibers. Many of them exhibit an apparently normal structure (n). An oligodendrocyte $(\mathrm{Od})$ is seen at the left superior quadrant of this field. Bar $=1.7 \mu \mathrm{m}$. B. A small-sized fibre is seen with the axoplasm filled with a dense and amorphous material, typical of dark degeneration (d). Normal looking fibers (n) are also observed. Bar $=0.25 \mu \mathrm{m}$. C. Periphery of the optic nerve. An optic fiber shows an extensive vacuolization and consequent delamination of myelin lamellae (arrows); the axoplasmic cytoskeleton is apparently preserved in this fiber. Normal looking fibers (n) are also observed. Portions of somata of an oligodendrocyte (Od) and a microglial cell (Mi) can be seen next to the glia limitans (gl) in this field. f, fibroblast in pia mater. Bar $=1.7 \mu \mathrm{m}$. D. A large astrocytic process contains lamellar debris (thick arrows) within its cytoplasm. Observe bundles of filaments (thin arrows) in the cytoplasmic process, typical of astrocytes. Normal (n) and altered (star) fibers (with axolemmal detachment from myelin) are seen. Bar $=1.1 \mu \mathrm{m}$. 


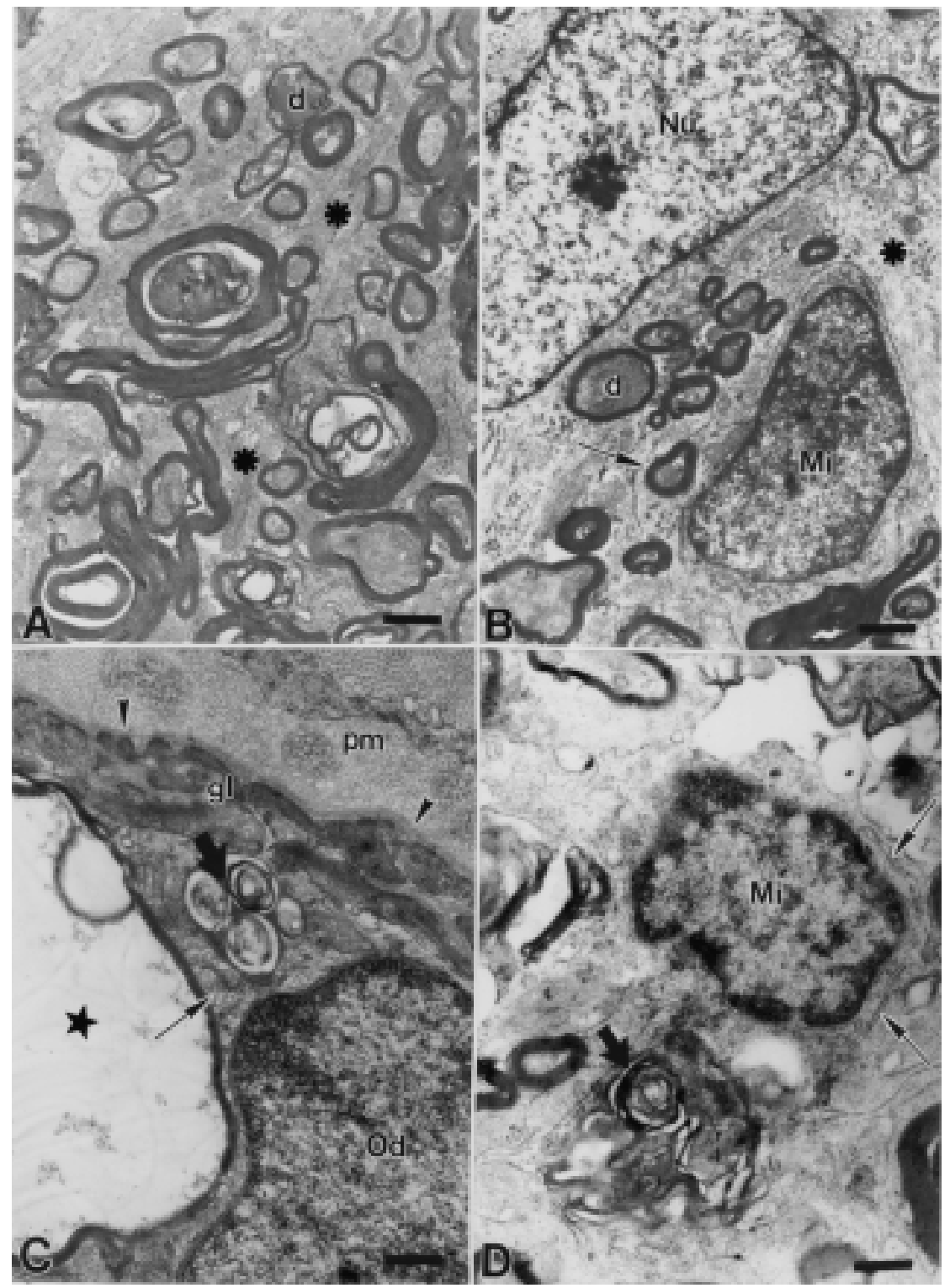

Fig. 4 - Electron micrographs of opossum's optic nerve fibers undergoing Wallerian degeneration, 168 hours after crush. A. Presence of many astrocytic processes (asterisks) causing distortion of the nerve fascicles. Note fibers with a dense axoplasm, typical of dark degeneration (d). Bar $=1.1 \mu \mathrm{m}$. B. A hypertrophic astrocyte, with thick hyperfilamentous processes (asterisk) and an euchromatic nucleus $(\mathrm{Nu})$ showing an evident nucleolus, is visualized in this field next to a microglial cell (Mi), which has scanty cytoplasm and a more heterochromatic nucleus. Note many fibers undergoing dark degeneration (d), and one of them seems to be engulfed by the microglia (arrow). Bar $=1.1 \mu \mathrm{m}$. C. Periphery of the optic nerve, in which we can observe astrocytic processes of the glia limitans (gl) abutting the basal lamina (arrowheads). Observe an enlarged fibre (star), with a pale axoplasm, devoid of organelles, showing typical watery degeneration. Next to it, is an oligodendrocyte (Od), whose cytoplasm exhibits many microtubules (thin arrow), and presents vacuoles containing myelin debris (thick arrow). pm, pia mater. Bar $=0.6 \mu \mathrm{m}$. D. Microglial cell (Mi) with much phagocytosed myelin debris (thick arrow) within its cytoplasm. Observe the slender REG cisternae (thin arrows) around the nucleus. Degenerating fibers and myelin debris occur in the neighbourhood. Bar $=0.6 \mu \mathrm{m}$. 
age products, which can occur at any level of the axon (Griffin et al. 1995). The mechanisms which underlie the cytoskeletal destruction at the onset of WD seem to be related to the activation of calciumsensitive proteases, or calpains, which could be responsible for the breakdown of the main axonal cytoskeleton proteins (Saito et al. 1993, Glass et al. 1994, George et al. 1995, Bartus 1997, Martinez and Ribeiro 1998). According to Schlaepfer (1977), the dissolution of axonal MT and NF is triggered by a calcium influx, due to the disturbance of the entire axolemma distal to the injury. It is possible that in WD calcium influx is triggered by ATP deprivation and failure of the $\mathrm{Na}^{+}-\mathrm{K}^{+}$-ATPase followed by reverse operation of the $\mathrm{Na}^{+}-\mathrm{Ca}^{2+}$-exchanger (Lo Pachin and Lehning 1997). If the increase in axoplasm calcium triggers microtubule and neurofilament breakdown, it is quite possible that calpains, which are normally present inside the axoplasm, are gradually activated leading to an increasing disintegration of the axoplasmic content. Accordingly, in the present study, some fibers in the opossum's injured optic nerve presented focal degeneration of the cytoskeleton at 24, 48, 72 and 96 hours after crush. So, based on our present and previous observations, we could probably say that axoplasm disintegration starts focally and spreads throughout the entire axon as a consequence of a gradual activation of calpains due to an increase in the axoplasmic calcium concentration. Our results, therefore, differ from previous descriptions (see Griffin et al. 1995) that say that cytoskeleton breakdown follows an "allor-none" pattern i.e. the degenerative changes in the cytoskeleton would not present intermediary stages of degeneration.

Both dark and watery degeneration as observed in the opossum's crushed optic nerve are similar to what has been observed in many vertebrates (Kruger and Maxwell 1969, Ishise and Rosenbluth 1986, Cook et al. 1974, Bignami et al. 1981, Cook and Wisniewski 1987, Carrol et al. 1992). These studies do not mention the mechanism that would induce one or other type of degeneration, nor do they describe morphological differences between these two patterns of axon degeneration. In fact there are very few articles dealing with this subject as pointed out earlier. Bignami et al. (1981) reported that there was a rapid disappearance of floccular axonal segments but denser axonal segments were maintained for longer periods in the optic nerve. It is well known that NFs are more resistant to granular disintegration, remaining in the axoplasm for a variable amount of time. Experiments using transection of sciatic nerve of rats (Schlaepfer et al. 1984) and mice (Glass and Griffin 1991) showed that NF undergo a slow and progressive redistribution in the distal segment, resulting on accumulations in the distal end of the isolated segment, indicating an incomplete degradation of NF protein during WD (Schlaepfer et al. 1984). In the present study we observed many dilated fibers with an accumulation of organelles, NF being particularly abundant in a central position. However, MTs were not clearly identified in these fibers. So, it seems reasonable to suggest that neurofilamentous accumulation and aggregation play a role in the process of dark degeneration.

In this study we present evidence of myelin breakdown in the presence of a normal or partially disrupted axoplasm. This result was also observed previously in our laboratory in rat sural nerve, 30 hours after crush (Martinez and Canavarro 2000). This finding is consistent with a direct injury to the myelin sheath following injury, which is explained by the presence of calpains inside astrocytes and Schwann cells during Wallerian degeneration (Ludwin 1995). So, it might be possible that there is a similar mechanism underlying both axon and myelin disruption, as we suggested previously (Martinez and Canavarro 2000).

Concerning the course of WD of the opossum's optic nerve, it was noted that at the initial stages of nerve fiber degeneration, there was no uniformity in the pattern of alteration, since degenerating fibers exhibited different features in the same nerve and at the same time. An apparent uniformity in the pattern of degenerative alterations was only achieved at later stages (168 hours after crush), when almost all 
optic fibers were undergoing degeneration. Thus, the degeneration of nerve fibers as seen in sections of opossum's optic nerve occurs in an asynchronous manner.

Morphological evidence of the asynchronous rate of WD has been achieved by different approaches. In a previous report, using axonal MT dissolution as a degenerative criterion in crushed fibers of rat sural nerve, we concluded that smalland large-sized fibers degenerated simultaneously in response to the crush injury (Malbouisson et al. 1985). Different rates of axonal degeneration were observed in crossed and uncrossed fibers in Monodelphis domestica (Guillery and Taylor 1993) but not in Didelphis marsupialis (Guillery and Cavalcante 1995). In the present study we did not address this question but we also observed early degenerative alterations in small and large nerve fibers at all stages considered. However, the right moment (or the triggering factors) for the recruitment of a certain nerve fiber for the degenerative pathway at any considered stage could not be established. So, the reasons that underlie the different vulnerability of nerve fibers to axotomy or other kind of lesion remain unknown.

Comparing the process of WD in CNS and PNS fibers is interesting, since it occurs in a general similar way, but shows specific patterns depending on the parameter that is being studied. The main comparative parameter is the velocity of the process. While in PNS WD occurs in hours or days, in CNS it proceeds at a slow rate, lasting for weeks and sometimes months (Donat and Wisniewski 1973, Joseph 1973, Lubinska 1977, David et al. 1990, Perry et al. 1990, Hall 1993, Reier 1995). Many factors are probably associated with this difference. Such factors include the reaction of glial (Carbonell et al. 1991, Blaugrund et al. 1992, Cadelli et al. 1992, Butt and Colquhoun 1996, Butt and Kirvell 1996) and phagocytic lineage cells (Avellino et al. 1995, David et al. 1990, Carbonell et al. 1991, Hall 1993, Lawson et al. 1994, Bruck 1997) which have a significant influence on the axons (for example, by production of cytokines and proteolytic enzymes -
Ludwin 1995), certainly providing a highly specific microenvironment which would allow different survival times of degenerating fibers according to the region of the nervous tissue that it belongs to. In the present study we report that nerve fiber degeneration of opossum optic nerve is almost complete one week after crush. This result is similar to that described for other mammals (Cook and Wisniewski 1987).

Since, at least in PNS, the most obvious function of WD is to prepare a way for potential axonal regeneration (Griffin et al. 1995), the search for answers on the regulative mechanisms of such a process makes it relevant in the sense of proposing the viability of this same function for CNS regeneration, which is still abortive, unknown and deceptive at experimental and clinical approaches.

\section{ACKNOWLEDGMENTS}

We are grateful to Dr. Monika Barth (FIOCRUZ Rio de Janeiro) for letting us use the Electron Microscope. The technical help given by Maír Machado de Oliveira is acknowledged.

CAPES, CNPq, FUJB, FINEP and FAPERJ (BRASIL) supported this work.

\section{RESUMO}

Neste trabalho, relatamos uma análise morfológica qualitativa da degeneração Walleriana em um marsupial. Os nervos ópticos direito de gambás da espécie Didelphis marsupialis foram esmagados com uma pinça fina. Após 24, 48, 72, 96 e 168 horas, os animais foram anestesiados e perfundidos com fixador. A seguir, os nervos foram imersos em fixador e processados para microscopia eletrônica de rotina. Entre as alterações precoces típicas da degeneração, observamos fibras nervosas com degeneração focal do citoesqueleto axoplasmático, degeneração aquosa e degeneração escura, com o último tipo prevalente às 168 horas após esmagamento. Nossos resultados indicam uma desintegração gradual do citoesqueleto axoplasmático, oposta à prévia visão de um processo "tudo-ou-nada". Relatamos também que, devido a um mecanismo desconhecido, as fibras mostram ou um padrão aquoso ou um padrão escuro de degeneração axonal, conforme obser- 
vado nos perfis axonais. Observamos também fibras cuja mielina sofria uma degradação precoce na ausência de alterações axonais.

Palavras-chave: ultra-estrutura, fibra nervosa, lesão por esmagamento, degeneração "fluida", degeneração escura, marsupial.

\section{REFERENCES}

Allodi S, Reese BE and Cavalcante LA. 1990. Observations on the arrangement of axons according to diameter in the optic tract of the opossum Didelphis marsupialis. Braz J Med Biol Res 23: 539-542.

Avellino AM, Hart D, Dailey AT, MacKinnon M, Ellegala D AND Kliot M. 1995. Differential macrophage responses in the peripheral and central nervous system during Wallerian degeneration of axons. Exp Neurol 136(2): 183-198.

Bartus RT. 1997. The calpain hypothesis of neurodegeneration: evidence for a common cytotoxic pathway. The Neuroscientist 3(5): 314-327.

Bignami A, Dahl D, Nguyen BT and Crosby CJ. 1981. The fate of axonal debris in Wallerian degeneration of rat optic and sciatic nerves. J Neuropathol and Exp Neurol 40(5): 537-550.

Blaugrund E, Duvdevani R, Lavie V, Solomon A AND Schwartz M. 1992. Disappearance of astrocytes and invasion of macrophages following crush injury of adult rodent optic nerves: implications for regeneration. Exp Neurol 118: 105-115.

BRUCK W. 1997. The role of macrophages in Wallerian degeneration. Brain Pathol 7(2): 741-752.

ButT AM And Colquhoun K. 1996. Glial cells in transected optic nerves of immature rats. I. An analysis of individual cells by intracellular dye-injection. J Neurocytol 25: 365-380.

ButT AM AND KIRvelL S. 1996. Glial cells in transected optic nerves of immature rats. II. An immunohistochemical study. J Neurocytol 25: 381-392.

Cadelli DS, Bandtlow CE and Schwab ME. 1992. Oligodendrocyte- and myelin-associated inhibitors of neurite outgrowth: their involvement in the lack of CNS regeneration. Exp Neurol 115: 189-192.
Carbonel AL, Boya J, Calvo JL and Marin JF. 1991. Ultrastructural study of the neuroglial and macrophagic reaction in Wallerian degeneration of the adult rat optic nerve. Histol Histopathol 6(4): 443-451.

Carrol EW, Curtis RL, Sullivan DA and Melvin JL. 1992. Wallerian degeneration in the optic nerve of the Wabbler-Lethal (wl/wl) mouse. Brain Res Bul 29: 411-418.

Cavalcante LA, Allodi S and Reese BE. 1992. Fiber order in the opossum's optic tract. Anat Embryol 186: $589-600$.

Cavalcante LA, Barradas PC and Martinez AMB. 1991. Patterns of myelination in the opossum superior colliculus with additional reference to the optic tract. Anat Embryol 183: 273-285.

Cook RD. 1978. Primary demyelination in cat optic nerves associated with surgically induced axonal degeneration. Neuropathol Applied Neurobiol 4(5): $357-368$

Cook RD AND Wisniewski HM. 1987. The spatiotemporal pattern of Wallerian degeneration in the Rhesus monkey optic nerve. Acta Neuropathol (Berlin) 72: 261-267.

Cook RD, Ghetti B And Wisniewski HM. 1974. The pattern of Wallerian degeneration in the optic nerve of newborn kittens: an ultrastructural study. Brain Res 75: 261-275.

Crevel H van and Verhatat WS. 1963. The rate of secondary degeneration in the central nervous system. II. The optic nerve of the cat. J Anat 97: 451464 .

David S, Bouchard C, Tsatas O ANd GifTOChristos N. 1990. Macrophages can modify the non-permissive nature of the adult mammalian CNS. Neuron 5: $463-$ 469.

Donat JR AND Wisniewski HM. 1973. The spatiotemporal pattern of Wallerian degeneration in mammalian peripheral nerves. Brain Res 53: 41-53.

Frank M And Wolburg H. 1996. Cellular reactions at the lesion site after crushing of the rat optic nerve. Glia, 16(3): 227-240.

George EB, Glass JD And GrifFin JW. 1995. Axotomy- 
induced axonal degeneration is mediated by calcium influx through ion-specific channels. J Neurosci 15(10): 6445-6452.

GLASS JD AND GRIFFIN JW. 1991. Neurofilament redistribution in transected nerves: evidence for bidirectional transport of neurofilaments. J Neurosci 11(10): 3146-3154.

Glass JD, Schryer BL AND GRIfFIN JW. 1994. Calcium-mediated degeneration of the axonal cytoskeleton in the Ola mouse. J Neurochem 62: 24722475 .

Griffin JW and Hoffman PN. 1993. Degeneration and Regeneration in the Peripheral Nervous System. In: Dick PJ, Thomas PK, Griffin JW, Low PA AND PoDUsLo JW (Ed.). Peripheral Neuropathy. Philadelphia: W. B. Saunders Company, p. 361-376.

Griffin JW, George EB, Hsieh S-T and Glass JD. 1995. Axonal degeneration and disorders of the axonal cytoskeleton. In: WAXMAN SG, Kocsis JD AND Stys PK (Ed.). The Axon. Structure, Function and Pathophysiology. New York, Oxford: Oxford University Press, p. 375-390.

Guillery RW and Cavalcante LA. 1995. A note on the relative rates of degeneration in the crossed and the uncrossed retinofugal fibers in the opossum Didelphis marsupialis. J Neurocytol 24: 155-158.

Guillery RW AND TAYlOR JSH. 1993. Different rates of axonal degeneration in the crossed and uncrossed retinofugal pathways of Monodelphis domestica. J Neurocytol 22: 707-716.

Hall SM. 1993. Observations on the progress of Wallerian degeneration in transected peripheral nerves of $\mathrm{C} 57 \mathrm{BL} / \mathrm{Wld}$ mice in the presence of recruited macrophages. J Neurocytol 22: 480-490.

Hasegawa M, Rosenbluth J And Ishise J. 1988. Nodal and paranodal structural changes in mouse and rat optic nerve during Wallerian degeneration. Brain Res 452: 345-357.

HoKoç JN ANd Oswaldo-CRuz E. 1978. Quantitative analysis of the opossum's optic nerve: An electron microscope study. J Comp Neurol 178(4): 773-782.

Ishise J AND Rosenbluth J. 1986. Nodal and paranodal structural changes in frog optic nerve during early Wallerian degeneration. J Neurocytol 15: 657-670.

JoSEPH BS. 1973. Somatofugal events in Wallerian degeneration: A conceptual Overview. Brain Res 59: $1-18$.

Kirby MA, Clift-Forsberg L, Wilson PD AND RapisARDI SC. 1982. Quantitative analysis of the optic nerve of the North American opossum (Didelphis virginiana): An electron microscopic study. J Comp Neurol 211: 318-327.

Kruger L and Maxwell DS. 1969. Wallerian degeneration in the optic nerve of a reptile: An electron microscopic study. Amer J Anat 125: 247-270.

Lawson LJ, Frost L, Risbridger J, Fearn S ANd Perry VH. 1994. Quantification of the mononuclear phagocyte response to Wallerian degeneration of the optic nerve. J Neurocytol 23: 729-744.

LiN H AND IngRAm WR. 1973. Axonal degeneration in the peripheral optic pathway of the cat. Exp Neurol 39: 234-248.

LopaChIN RM AND LeHNING EJ. 1997. Mechanism of calcium entry during axon injury and degeneration. Toxicol Appl Pharmacol. 143: 233-244.

LUBINSKA L. 1977. Early course of Wallerian degeneration in myelinated fibers of the rat phrenic nerve. Brain Res 130: 47-63.

LUDWIN SK. 1995. Pathology of the myelin sheath. In: Waxman SG, Kocsis JD and Stys PK (Ed.). The Axon. Structure, Function and Pathophysiology. New York, Oxford: Oxford University Press, p. 412-437.

Lunn ER, Brown MC and Perry VH. 1990. The pattern of axonal degeneration in the Peripheral Nervous System varies with different types of lesion. Neuroscience 35(1): 157-165.

Malbouisson AMB, Ghabriel MN and Allt G. 1984. The non-directional pattern of axonal changes in Wallerian degeneration: A computer-aided morphometric analysis. J Anat 139(1): 159-174.

Malbouisson AMB, Ghabriel MN and Allt G. 1985. Axonal degeneration in large and small nerve fibers - An electron microscopic and morphometric study. 
J Neurol Sci 67: 307-318

Martinez AMB And Canavarro S. 2000. Early myelin breakdown following sural nerve crush: a freezefracture study. Braz J Med Biol Res 33(12): 14771482 .

Martinez AMB and Ribeiro LCV. 1998. Ultrastructural localization of calcium in peripheral nerve fibers undergoing Wallerian degeneration: an oxalatepyroantimonate and X-ray microanalysis study. J Submicrosc Cytol Pathol 30(3): 451-458.

Perry VH, Brown MC, Lunn ER, Tree P and Gordon S. 1990. Evidence that very slow Wallerian degeneration in C57BL/Ola mice is an intrinsic property of the peripheral nerve. Eur J Neurosc 2: 802-808.

Peters A, Palay SL and Webster HF. 1991. The Fine Structure of the Nervous System - Neurons and Their Supporting Cells. Third Edition, Oxford University Press.

ReIER PJ. 1995. Degeneration and Regeneration in the Nervous System In: ConN P.M (ed). Neuroscience in Medicine. Philadelphia: J B Lippincott Company, p. $593-619$.
Saito K-, Elce JS, Hamos JE and Nixon RA. 1993. Widespread activation of calcium-activated neutral proteinase (calpain) in the brain in Alzheimer disease: A potential molecular basis for neuronal degeneration. Proc Nat Acad Sci USA 90: 2628-2632.

SCHLAEPFER WW. 1977. Structural alterations of peripheral nerve induced by the calcium ionophore A23187. Brain Res 136: 1-9.

Schlaepfer WW, Lee C, Trojanowski JQ and Lee VM-Y. 1984. Persistence of immunoreactive neurofilament protein breakdown products in transected rat sciatic nerve. J Neurochem 43(3): 857-864.

WALler AV. 1850. Experiments on the section of the glossopharyngeal and hypoglossal nerves of the frog, and observations of the alterations produced thereby in the structure of their primitive fibers. Phil Transac Royal Soc London 140: 423-429.

Waxman SG, Black JA, Stys PK and Ransom BR. 1992. Ultrastructural concomitants of anoxic injury and early post-anoxic recovery in rat optic nerve. Brain Res 574: 105-119.

Waxman SG, Black JA, Ransom BR and Stys PK. 1993. Protection of the axonal cytoskeleton in anoxic optic nerve by decreased extracellular calcium. Brain Res 614: 137-145. 